\title{
Promoção do aleitamento materno: políticas públicas e atuação do enfermeiro
}

\section{Promotion of breastfeeding: public policies and nurse's activities}

\author{
1 Débora Stéffanie Sant'Anna da Silva \\ 1 Monique de Oliveira \\ 2 Ana Lucia Torres Devezas Souza \\ 3 Renata Martins da Silva renataenfprofessora@gmail.com
}

\footnotetext{
1 Bacharelado em Enfermagem pelo Centro Universitário de Volta Redonda (UniFOA)

2 Docente Curso de Enfermagem (UniFOA). Mestre em Ensino de Ciências da Saúde e Meio Ambiente.

3 Docente Curso de Enfermagem (UniFOA). Mestre em Ensino de Ciências da Saúde e Meio Ambiente. Doutoranda do PPGENFBIO (UNIRIO)
}

\section{Resumo}

Este estudo teve por objetivos discutir cuidados de enfermagem, evidenciados na literatura, para promover o aleitamento materno e destacar políticas públicas de incentivo dessa prática. A pesquisa utilizou abordagem qualitativa, na qual foram analisados 31 artigos, 5 teses e 4 Manuais do Ministério da Saúde publicados entre os anos de 2000 a 2015, utilizando-se os descritores: aleitamento materno, cuidados de Enfermagem, promoção da saúde e políticas públicas. Os resultados demonstraram o papel de educador do enfermeiro no incentivo ao aleitamento e a importância das políticas públicas para apoiá-lo nas questões biológicas, humanas e sociais. Conclui-se que, no decorrer das décadas de $80 / 90$ até os dias atuais, Políticas Públicas foram implementadas no país, visando descender os índices de desmame precoce e mortalidade infantil, proporcionando novos horizontes e metas para auxiliar as instituições e profissionais de saúde a promoverem cuidados padronizados e um melhor atendimento às gestantes/puérperas e recém-nascidos, em relação à prática do aleitamento materno.

\section{Palavras-chave}

Aleitamento materno; cuidados de enfermagem; promoção da saúde; políticas públicas.

\begin{abstract}
This study aimed to discuss nursing care, evidenced in the literature, to promote breastfeeding and to highlight public policies to encourage this practice. The research used a qualitative approach, in which 31 articles, 5 theses and 4 Manuals of the Ministry of Health published between the years 2000 to 2015 were analyzed, using the descriptors: breastfeeding, Nursing care, health promotion and public policies. The results demonstrated the role of the nurse in encouraging breastfeeding as an educator and the importance of public policies to support him in biological, human and social issues. In the course of the 1980s and 1990s, public policies were implemented in the country, aiming at lowering rates of early weaning and infant mortality, providing new horizons and goals to assist health institutions and promote standardized care and better care for pregnant women / new mothers and newborns in relation to breastfeeding.
\end{abstract}

\section{Keywords}

Breastfeeding, Nursing Care, Health Promotion and Public Policies.

\section{Como você deve citar?}

SILVA, Débora Stéffanie Sant'Anna da et al. Promoção do aleitamento materno: políticas públicas e atuação do enfermeiro. Cadernos UniFOA, Volta Redonda, n. 35, p. 135-140, dez. 2017. 


\section{INTRODUÇÃO}

O aleitamento materno é a mais sábia estratégia natural de vínculo, afeto, proteção e nutrição para a criança e constitui a mais sensível, econômica e eficaz intervenção para redução da morbimortalidade infantil (MINISTÉRIO DA SAÚDE, 2015). A excelência do aleitamento materno é incontestável, apesar de sofrer influência das crenças e mitos arraigados na cultura de cada pessoa, porém é de grande divulgação os benefícios dessa prática tanto para mãe quanto para o bebê, a família e a sociedade.

Sua importância ficou suficientemente demonstrada, especialmente em relação à prevenção da desnutrição e gastroenterite, uma vez que, garantindo o aleitamento materno até o sexto mês de vida, a criança alcança o crescimento e desenvolvimento de forma mais segura, eficaz e completa (CARVALHO, 2014).

O profissional de enfermagem atua diretamente no incentivo ao Aleitamento Materno, pois possui maior contato direto com as puérperas e neonatos, estando presente nos períodos de pré-natal, puerpério imediato, mediato e tardio. Dessa forma, a implantação de intervenções, por meio de ações intra-hospitalares e interinstitucionais, proporcionadas por profissionais habilitados e capazes de realizar cuidados de enfermagem que visam ao auxílio na promoção de uma pega adequada e cuidados com os seios, se torna eficaz na medida em que são implementadas e trazem benefícios para a nutriz e recém-nascidos (CUNHA e SIQUEIRA, 2016).

Para promoção do aleitamento materno, várias políticas públicas foram criadas com o intuito de incentivar, promover e apoiar essa prática. Devido às transformações sociais, ocorreram mudanças de valores quanto ao aleitamento materno, o que requereu ações do Estado com a instauração de políticas de incentivo à amamentação (PINHEIRO, GALIZA e FONTOURA, 2009)

Diversas medidas foram instituídas para incentivar a amamentação como: a criação dos bancos de leite; projeto Carteiro Amigo; destacando-se, atualmente, a Iniciativa Hospital Amigo da Criança, criado pelo Fundo nas Nações Unidas para a Infância (UNICEF), juntamente com a Organização Mundial de Saúde (OMS); Alojamento Conjunto (AC) e a Rede Cegonha (SIQUEIRA, 2017).

Na prática da amamentação no período pré-natal e puerperal, o Ministério da Saúde criou a Iniciativa Unidade Básica Amiga da Amamentação (IUBAAM), atuando em conjunto com a Rede Amamenta Brasil (RAB), ambas visando capacitar os profissionais públicos de saúde para atuarem na promoção do aleitamento materno, nos serviços de saúde (MINISTÉRIO DA SAÚDE, 2015).

\section{OBJETIVOS}

O objetivo do estudo foi discutir cuidados de enfermagem, evidenciados na literatura, para promover o aleitamento materno e destacar políticas públicas de incentivo dessa prática.

\section{METODOLOGIA}

Trata-se de uma revisão bibliográfica sobre as medidas de promoção do aleitamento materno embasadas em políticas públicas vigentes e que subsidiam a atuação do enfermeiro, buscando auxiliar na ascendência da prática de amamentar. A pesquisa utilizou abordagem qualitativa, pois é o método que privilegia a investigação dos significados das relações humanas, buscando a melhor compreensão da temática a ser estudada, facilitando a compreensão dos dados obtidos. 
Foram utilizadas fontes disponíveis em bases de dados através da Biblioteca Virtual em Saúde (BVS), BIREME, SCIELO e banco de teses, utilizando-se os seguintes descritores: aleitamento materno, cuidados de enfermagem, promoção da saúde e políticas públicas.

Foram analisados 31 artigos, 5 teses e 4 Manuais do Ministério da Saúde publicados entre os anos de 2000 a 2015. A busca foi realizada no período de julho a setembro de 2015 . Utilizou-se como critério de inclusão textos que abordavam de forma unificada os descritores citados acima, publicados em português.

Foi realizada uma análise criteriosa dos textos selecionados e utilizados para pesquisa, selecionando-se os que mais se aproximavam da temática. Após realizado o fichamento contendo as principais ideias de cada texto e a análise individual de cada artigo, eles foram agrupados por unidades temáticas nas seguintes categorias: cuidados de enfermagem e a promoção do aleitamento materno e políticas públicas de incentivo ao Aleitamento Materno (AM).

\section{RESULTADOS E DISCUSSÃo}

\subsection{Cuidados de Enfermagem e a promoção do Aleitamento Materno}

A maioria dos textos analisados traz discussões sobre a importância da capacitação do Enfermeiro, nos níveis de conhecimentos técnicos e científicos, para executarem uma abordagem de excelência para a promoção, apoio e incentivo à amamentação. Apontam, ainda, para a importância da abordagem a respeito do Aleitamento Materno no pré-natal, de forma a aumentar os índices de adesão da prática nos primeiros seis meses de vida da criança.

Em estudo realizado em Marília (SP), afirma-se que o despreparo dos profissionais de saúde que acompanham as mulheres no período gravídico-puerperal e as crianças no período de nascimento e de puericultura, associado à conduta, a rotinas, a práticas inadequadas nos serviços de saúde, contribui para o desmame precoce. Por isso, o profissional deve estar preparado e demonstrar segurança frente ao manejo do aleitamento na maternidade e após a alta (SIQUEIRA, 2017).

Foi destacado na literatura que uma boa comunicação é essencial para a promoção do Aleitamento Materno, visto que se faz necessária uma fala mais clara e objetiva, evitando-se uma linguística rebuscada e técnica, com o objetivo de facilitar o entendimento das informações por parte da gestante/ puérpera, tornando-a autônoma no processo de amamentar e capaz de reconhecer suas necessidades de aprendizado.

Observou-se que os cuidados de enfermagem mais citados foram: trabalhar mitos, crenças e tabus a respeito da amamentação; estimular a participação da família nas ações de promoção, apoio e incentivo ao aleitamento materno e dialogar a respeito das vantagens do aleitamento. Práticas educativas; orientação sobre o manejo do Aleitamento Materno; respeito à ótica materna, bem como suas decisões; orientação sobre a pega do recém-nascido e os riscos do uso de bicos e mamadeiras e também os cuidados pós-natal; importância do enfermeiro para a promoção do aleitamento materno em transmitir, junto à mãe, segurança em sua capacidade de amamentar, respondendo às dúvidas vivenciadas por ela, foram temas também discutidos nos textos pesquisados.

Cabe ao enfermeiro estimular a participação das pessoas que pertencem ao ciclo social da gestante/puérpera, desde as consultas pré-natais e incluí-los em atividades em conjunto com ela, para assim poder prevenir e sanar dúvidas que necessitem de aconselhamento do enfermeiro. 0 aconselha- 
mento é uma forma de atuação do profissional com a mãe em que ele a escuta, procura compreendê-la e, com seus conhecimentos, oferece ajuda para propiciar que planeje, tome decisões e se fortaleça, aumentando sua autoconfiança e autoestima (SIQUEIRA, 2017).

As medidas de promoção do aleitamento materno, como a realização de grupos no pré-natal e as visitas domiciliares nas semanas que sucedem ao parto são estratégias praticadas pelos enfermeiros para estimular a participação familiar junto à gestante, nas ações realizadas para promoção do aleitamento (CUNHA e SIQUEIRA, 2016)

Os meios de incentivo, divulgação e instrumentos para aproximar as gestantes e esclarecer dúvidas mais mencionadas nos textos foram: os grupos de apoio/mães; a importância do vínculo entre o profissional e a gestante/puérpera para estabelecer um bom aconselhamento; palestras; uso de jogos educativos, material visual e de leitura, programas de educação e sessões individuais.

Carascoza (apud MOTA, 2015) relata que o Ministério de Saúde junto com os profissionais tem promovido campanhas de sensibilização através de palestras, da comunicação social, no que toca aos fatores e aos mitos ligados ao aleitamento materno e ao desmame.

A promoção em saúde visa apontar meios de se divulgar o Aleitamento Materno (vantagens para a mãe, bebê, sociedade e ambiental), propondo-se, através de medidas de divulgação (campanhas, visitas domiciliares, palestras, etc.), atingir não somente a gestante/puérpera, mas sim todo o contexto em que ela se encontra inserida, tanto socialmente quanto culturalmente, para que assim ela possa encontrar apoio em seu ciclo familiar/social e praticar o aleitamento de forma segura e autônoma.

\subsection{Políticas Públicas de Incentivo ao Aleitamento Materno (AM)}

Com a entrada da mulher no mercado de trabalho, mais significamente nos anos 70 do século passado, há cerca de três décadas, a Organização Mundial da Saúde (OMS) e o Fundo das Nações Unidas pela Infância (UNICEF), com o apoio de organizações governamentais e não governamentais em todo o mundo, passaram a direcionar esforços para promover uma política de incentivo à amamentação, visando à diminuição dos índices de desmame precoce e de morbimortalidade infantil (KALIL e COSTA, 2012).

O Programa Nacional de Incentivo ao Aleitamento Materno (PNIAM) foi apontado como a gênese de uma nova mentalidade acerca do Aleitamento Materno, impulsionando as Políticas Públicas Brasileiras para um processo de aperfeiçoamento e modificação, visando a uma nova ótica sobre a promoção, apoio e incentivo à amamentação. Vale ressaltar que a Política Nacional de Promoção, Proteção e Apoio ao Aleitamento Materno contempla seis estratégias centrais: a Rede Amamenta Brasil; a Rede Brasileira de Bancos de Leite Humano (Rede BLH-BR); a Iniciativa Hospital Amigo da Criança (IHAC); a Proteção Legal ao Aleitamento Materno; o Monitoramento dos Indicadores de Aleitamento Materno; e a Mobilização Social (KALIL e COSTA, 2012).

O alojamento conjunto e a Iniciativa Hospital Amigo da Criança (IHAC) são programas de extrema importância para promoção, apoio e implementação do Aleitamento Materno, com viabilização de medidas para assistência padronizada para atuação do profissional de saúde, bem como sua melhor qualificação, e também padronização das instalações de saúde para aporte à Amamentação (MINISTÉRIO DA SAÚDE, 2015).

Como apoio ao Aleitamento Materno, foram instituídos os direitos da mulher. A partir da promulgação da Constituição Federal de 1988, ficaram garantidos importantes direitos, abrangendo a licença-maternidade de 120 dias e licença-paternidade, bem como a licença às mulheres presidiárias. 
E, ainda, ressalta-se a Norma Brasileira de Comercialização de Alimentos para Lactentes e Crianças de Primeira Infância (NBCAL), padronizando e minimizando a divulgação e comércio de soluções lácteas industrializadas, chupetas e mamadeiras; e a importância dos Bancos de Leite Humano na descendência dos índices de desmame precoce (MOTA, 2015).

Nos dias atuais, a Rede Cegonha, instituída no âmbito do Sistema Único da Saúde (SUS), pela Portaria ${ }^{0} 1.459$, de 24 de junho de 2011, fundamenta-se nos princípios da humanização e da assistência, que asseguram às crianças, o direito ao nascimento seguro, ao crescimento e ao desenvolvimento saudáveis, apoiando e dando subsídios para a Estratégia Amamenta e Alimenta Brasil, que resultou na integração das ações da Rede Amamenta Brasil e da Estratégia Nacional de Promoção da Alimentação Complementar Saudável (Enpacs), lançadas em 2008 e 2009, respectivamente, com a finalidade de promover a reflexão da prática da atenção à saúde de crianças de 0 a 2 anos de idade e a capacitação dos profissionais de saúde para atuarem no aleitamento materno (MINISTÉRIO DA SAÚDE, 2015).

\section{CONCLUSÃO}

Constatou-se que a atuação do Enfermeiro é abrangente, pois ele possui maior contato com as gestantes/puérperas. Foi ressaltada a importância da capacitação desse profissional para melhor atender e incentivar o aleitamento, bem como colocar em prática as medidas-base das políticas vigentes no país, de incentivo e promoção ao aleitamento, desde o período pré-natal, visto que há um maior tempo para o preparo físico e psicológico para o ato de amamentar, fazendo-se necessário um relacionamento baseado no respeito e apoio do profissional junto à gestante/puérpera, bem como estímulo da participação das pessoas do ciclo social nas atividades desenvolvidas junto a elas.

Com este estudo, identificou-se que as políticas públicas são indispensáveis para a consolidação das medidas de promoção, apoio e incentivo ao Aleitamento Materno, e que, por meio delas, foi possível estabelecer um conjunto de metas que foram aprimoradas no decorrer dos anos, auxiliando em uma padronização dos cuidados de enfermagem, visando à melhoria no atendimento e ascendendo os índices de adesão à prática no decorrer das décadas; Conclui-se que, no decorrer das décadas de 80/90 até os dias atuais, muitas medidas/ações, políticas públicas foram implementadas em nosso país, visando descender os índices de desmame precoce e de mortalidade infantil, proporcionando novos horizontes e metas para auxiliarem as instituições e profissionais de saúde a promoverem instalações e cuidados padronizados, para melhor atendimento as gestantes/puérperas e recém-nascidos. 


\section{REFERÊNCIAS}

BRASIL. Ministério da Saúde. Secretaria de Atenção à Saúde. Departamento de Atenção Básica. Saúde da criança: aleitamento materno e alimentação complementar. 2. ed. - Brasília : Ministério da Saúde, 2015.

BRASIL. Ministério da Saúde. Secretaria de Atenção à Saúde. Estratégia Nacional para Promoção do Aleitamento Materno e Alimentação Complementar Saudável no Sistema Único de Saúde: manual de implementação. Brasília : Ministério da Saúde, 2015.

CARVALHO, Ocília Maria Costa. et al. Prevalência dos diagnósticos de enfermagem de amamentação no binomio mãe - filho em Unidade Básica de Saúde. Rev. Rene. V. 15, n.1, p.99-107. 2014. Disponível em: $<$ http://www.revistarene. ufc.br/revista/index.php/revista/article/view/1482/pdf $>$. Acesso em: 20 nov. 2016.

CUNHA, E.C.; SIQUEIRA, H.C.H. Aleitamento Materno: Contribuições da Enfermagem. Ensaios Cienc., Cienc. Biol. Agrar. Saúde, v. 20, n. 2, p. 86-92, 2016.

KALIL, I.R.; COSTA, M.C. "Nada mais natural que amamentar". Discursos contemporâneos sobre aleitamento materno no Brasil. RECIIS - R. Eletr. de Com. Inf. Inov. Saúde. Rio de Janeiro, v.6, n.4, Dez., 2012.

MOTA, Cátia. 0 desmame precoce pela substituição do aleitamento natural por artificial: intervenção de enfermagem. Mindelo, 2015. 93f. Monografia - Escola de Enfermagem, Universidade do Mindelo.

PINHEIRO, Luana.; GALIZA, Marcelo.; FONTOURA, Natália. Novos arranjos familiares, velhas convenções sociais de gênero: a licença-parental como política pública para lidar com essas tensões. Estudos Feministas, Florianópolis, v.17, n. 3, p.851-859, 2009. Disponível em: < http://www.scielo.br/pdf/ref/ v17 n3/v17n3a13> Acesso em: 20 nov. 2016.

SIQUEIRA, Fernanda Paula Cerântula et al. A capacitação dos profissionais de saúde que atuam na área do aleitamento materno. Investigación en Enfermería: Imagen y Desarrollo [en linea] 2017, 19 (EneroJunio) Disponível em: <http://www.redalyc.org/articulo.oa?id=145249416012>. Acesso em: 20 nov. 2016. 